\title{
Learning Object Design and Development in Folklore Education Using Web 2.0 Tools
}

\author{
Alexandros Kapaniaris \\ PhD Candidate in Folklore, \\ Department of Science Education and Educational Design, \\ University of the Aegean, Rhodes, Greece \\ Email: a.kapaniaris@aegean.gr \\ Maria Gasouka \\ Assistant Professor in Folklore and Gender, \\ Department of Science Education and Educational Design, \\ University of the Aegean, Rhodes, Greece \\ Email: mgasouka@rhodes.aegean.gr
}

Dimitris Zisiadis

Research Associate, Department of Computer \& Communication Engineering, University of the Thessaly, Volos, Greece Email:dimitris@uth.gr

\section{Eleni Papadimitriou}

Teacher of Preschool education, Department of Early Childhood Education, University of the Thessaly, Volos, Greece

Email: elpapadi@uth.gr

\section{Evangelia Kalogirou}

M.Ed. Candidate, University of Nicosia, Cyprus Email: lilia.kalogirou@yahoo.gr

\section{Doi:10.5901/mjss.2013.v4n11p104}

\section{Abstract}

This paper refers to the design and development of learning objects in folklore education using available Web 2.0 technologies, in order to effectively address teaching folk culture in a classroom. More specifically, the role of learning objects as enriching digital resources in e-books is presented along with their role as learning assets that can function independently in the learning process. Moreover, learning objects are classified based on their characteristics either as simple learning objects, namely learning assets, or as complex learning objects in which case they constitute learning resources. At the same time we make a reference to learning objects with educational learning object metadata in accordance with international standards. The paper focuses on a) the development of learning objects in folklore teaching using web 2.0 tools in the context of enriched e-book creation («digital school» framework), b) the implementation of worksheets as part of ICT-enhanced teaching scenarios in folklore teaching along with their interconnection with appropriate learning objects as enriching digital resources.

Keywords: web 2.0, enriched e-book, folklore, learning object, learning object metadata

\section{Introduction}

Using Web 2.0 tools in learning object development in the context of enriched e-book creation is a challenge in the fields of folk culture and education. Teachers are able to create raw material for new enriched e-books by using Web 2.0 authoring tools and digital enrichment tools, while most of them are distributed as freeware. However the design of 
simple and complex learning objects must meet certain requirements and follow a wider pedagogical design. The purpose of educational learning object development is on one hand to be used independently and be available to educational learning repositories and on the other hand to add value in the e-book enrichment process.

\section{Learning Objects}

Learning objects, when used as part of a digital enrichment process, are called digital enrichment learning resources. Digital enrichment resources when combined with the proper pedagogic/teaching plan form the basic assets of the digital enrichment of electronic books. Therefore, it is important to analyse the learning object concept and also to define a learning object taxonomy.

A lot of efforts have been made to define and describe learning objects, in order to facilitate their deployment, where an ad-hoc terminology was adopted by each project, like «pedagogic documents» (ARIADNE, 2000), «education software ingredients» (ESCOT, 2000), «learning material provided through the Internet» (MERLOT, 2000) (Stefanou, 2002). Despite all those efforts for the definition of the learning object concept there was lack of a common conceptual definition from the educational community and all the stakeholders. However, there was a consensus in distance learning community as far as the functional requirements of learning objects are concerned. The functional requirements of learning objects are: a) accessibility, which must be described with proper metadata to allow database storage and retrieval, b) reusability, to allow usage in different educational contexts, c) interoperability, to ensure platform and Knowledge Management System independency (Polsani, 2003).

Several definitions can be found in the literature, which have as a common characteristic learning object reusability. Wiley defines learning object as every digital content source that can be reused to support learning (Wiley, 2001). L'Allier (1997) refers to learning object as the smallest independent structural experience that includes a learning goal, a learning activity and an evaluation. Learning object is an autonomous and independent education material unit that by definition embeds the possibility to be reused in different educational contexts (Polsani, 2003). Learning Technology Standards Committee (L.T.S.C.) definition states that learning objects are defined as entities, digital or not, that can be reused by different teaching systems and educational environments (IEEE 2002).

Taking all the above efforts into account we end up with the definition of learning object as an autonomous and independent education material unit associated with one or more learning goals, which has been constructed in such a way that it can be reused in different educational contexts.

\subsection{Learning Objects Taxonomy}

Digital enrichment resources are mapped based on their educational use in two types of learning objects: a) simple learning object (learning asset), b) complex learning object (learning resource) (IEEE 2002). Attempting to define a taxonomy for the simple and complex learning objects according to the definition above, we end up with the following representative objects (Kapaniaris \& Papadimitriou, 2012):

- Learning assets: image, simulation, text, experiment, sound, exploration, video, open activity, model, research activity, data representations.

- Learning resources: project, educational game, practice and training, evaluation, case study, demonstration, presentation, educational scenario - lesson plan, role play, glossary, guide, textbook, webcast, webpage, blog, wiki, social media.

\subsection{Technical and Functional Learning Object Requirements}

Digital learning objects are intended as digital enrichment resources in digitally enriched books, usually in html, or for deposit into digital educational repositories from where they can be retrieved and downloaded to a PC user locally. During the design and development phase of learning objects the following technical and functional requirements must be taken into account:

- Learning objects must rely on some learning theory (constructivism, behaviourism) depending on the learning goal and the teaching context they serve.

- Learning objects must provide added value to the learning process as well as the educational material with which they are combined.

- Learning objects must have an "Info" button which opens an informational card displaying the title and the 
relative unit that the learning object belongs to, the creators, the date of publication, copyright (relevant statements), as well as a statement if it has used part of another learning object.

- Learning objects must have a "Help" button that provides convenient and readable instructions/help info utilization of the digital learning object.

- Learning objects must be created in a form that can be posted on the web or in another multimedia application (html, htm, swf, ppt, word, xml, flv, mp3 etc.).

- Learning objects must be compatible with the available browsers (IE, Mozilla Firefox, Opera, Google Chrome, Safari, etc.).

- Operation in relation to the dimension of the learning object in order to allow shadowbox operation.

- Learning object must be accompanied by Metadata, which are declared following its construction according to the standard.

- Technical requirements must be stated for the learning object operation (plug-in).

\subsection{Learning Object Metadata}

Metadata are data describing other data that are created to facilitate information search, organization of digital resources and to facilitate issues related to interoperability of applications and archiving and preservation of digital resources. Based on their content metadata are divided in descriptive, structural or administrative metadata. The most popular international standard for learning object description with educational metadata is IEEE LOM (Learning Object Metadata). IEEE LOM is an international standard for educational resources characterization, aimed for storage, search and retrieval through repositories over the Internet (Kapaniaris \& Papadimitriou, 2012; IEEE 2002).

\section{Repositories and Learning Objects: The Case of Photodentro (Digital School in Greece)}

Photodentro was designed from the Greek Ministry of Education as part of the «Digital School» initiative in order to be the National Digital Repository of learning objects for the Primary and Secondary education. Its basic goal is to become the central access point to digital educational content and it is open to all, students, teachers, parents, as well as anybody else interested (http://photodentro.edu.gr).

The basic functions of Photodentro concern storage of reusable learning objects, developed by: a) teachers in the project «Specifications of Digital Educational Platform, Development and Operation of Digital knowledge base, Digital Modulation and Technical Metacommenting of Educational Material, Infrastructure for Exemplary Teaching and Utilization of Participatory Web», b) relative projects for educational software, funded by the Greek Ministry of Education, c) relative projects for the creation of educational software from the Pedagogic Institute, d) other sources (Kapaniaris \& Papadimitriou, 2012).

Photodentro's basic categories with the relative metadata fields are:

- General learning object data (language, description, keywords, author, edition, deposit date.

- Intended Audience (Educational level, Typical age range).

- Learning object sorting (Theme / Topic / Concept, Coverage / Period / Geographical area or other specialization, Type).

- Technical data and Requirements (Form, Object location (URL/URI), Technical Requirements).

- Use and Distribution Rights (Description of Use/Distribution license).

- Other information (Collections where it appears in the repository).

\section{Pedagogic Design of Learning Objects}

The pedagogical design of learning objects should follow specific pedagogical philosophy in relation to information and communication technologies (ICT). The learning theories that support the design of simple learning objects (learning asset) as image, audio, video, data representations, demonstration, presentation, practice and training, applications for evaluation, etc., belong to behaviourism.

In behavioural approaches, applications can be used either to provide supervisory teaching or to consolidate low level of knowledge and skills. Sometimes they are exploited as a means of assessing student performance. Specifically, Skinner's method is implemented through training programs and practice, Crowder's through mentoring schemes, while 
Gagne's through various multimedia applications (Komis, 2004).

The design of learning objects following behavioural theories should have the following characteristics:

- To actively engage user.

- To ensure fast and corrective feedback to the user actions.

- To provide the possibility of practicing a concept, idea, skill.

- To reward user for positive results.

- To provide the possibility of multiple representations and visualizations of the presented material (Siasiakos, 2009; Komis, 2004).

The learning theories that support the design of complex learning objects (learning resources) as simulation, experiment, exploration, open activity, model, activity, educational game, etc. belong to cognitive theories. The constructivism as a leading exponent of cognitive theories is a learning philosophy founded on the principle that learning occurs through reflection of experiences on which the personal knowledge of the world is built. Each of us creates his own "rules" and "mental schemas" in order to give meaning to his/her experiences (Kapaniaris \& Papadimitriou, 2012; Komis, 2004). Design of learning environments that arises from the constructivist/constructionist theories should have the following characteristics:

- To provide the opportunity to explore an area.

- To favour reconstruction of an idea, phenomenon, event.

- To offer the possibility to the user to shape multiple perspectives.

- To provide authentic learning activities.

- To expose the user to open-ended problems.

- To ease expression of ideas and opinion exchange.

- To facilitate user experimentation (Siasiakos, 2009; Komis, 2004).

Moreover, it is important to incorporate in the digital learning object designing: a) advice and guidance on reading/using/student and teacher engaging through footnotes and colour annotations (normal, interesting, remarkable, critical, attention), b) supporting information and resources (in our case on folk culture issues and c) targeted exploration and discovery opportunities so that the student can build his personal knowledge through his own learning path (Gasouka, Kapaniaris, Arvanitidou, Foulidi \& Raptou, 2013).

\section{Using Web 2.0 Tools to Create Learning Objects in Folklore Education}

The new digital culture formed in the Internet and the importance of teaching folk culture in education leads to the utilization of all digital media in the field of folklore. According to Gasouka \& Foulidi (2012) relationship between folklore, Internet and related digital media is of great interest. Specifically, the folkloric dimension of «Web 2.0» and related digital media helps in regeneration of folk culture (habits, beliefs, myths, tales, practices, attitudes, norms, etc.). Also Mixahl in Gasouka \& Foulidi (2012) characterizes the Internet world as a literal folk world and argues that "the Internet is an opportunity for a second life or online life is a second life, which is not a caricature of the former. On the contrary, it is a comprehensive new life, a «vita nuova». This is important for human «interneticus». He lives a life in parallel with the first one" (Gasouka \& Foulidi, 2012).

With the help of digital learning objects embedded in enriched digital books, students have the opportunity to come in contact with fairy tales, myths, riddles, folk songs, folk art and traditional crafts in a completely interactive way where participation and the individual learning path of the student is self-controlled in a fairly constructive way (Gasouka, et al., 2013).

By using Web 2.0 tools we can create free simple and complex learning objects (digital stories, presentations, photo gallery with free templates, quizzes, puzzles, comics, activities, etc.) that we can export constituting independent learning objects. Then, objects can be incorporated into a process of enriching digital books or they can be placed in educational repositories of learning resources. Table 1 presents some indicative Web 2.0 tools.

Table 1: Web 2.0 tools for learning object creation.

\begin{tabular}{|l|l|l|}
\hline Hot Potatoes & http://hotpot.uvic.ca/ & Crossword puzzles, quizzes, activities \\
\hline Cmap Tools & http://ftp.ihmc.us/ & Conceptual Maps \\
\hline Comic Strip Creator & http://www.comicstripcreator.org/ & Digital Comic \\
\hline flashmo.com & http://www.flashmo.com/ & Free flash templates \\
\hline
\end{tabular}




\begin{tabular}{|l|l|l|}
\hline Prezi & http://prezi.com/ & Interactive Presentations \\
\hline Audacity & http://audacity.sourceforge.net/ & Sound files \\
\hline Google earth & http://www.google.com/earth/index.html & Tour files \\
\hline Eclipse Crossword puzzle & http://www.eclipsecrossword.com/ & Crossword Puzzles \\
\hline Geogebra & http://www.geogebra.org/cms/en/ & Learning object creation in mathematics \\
\hline Jigsaw Puzzle & http://thejigsawpuzzles.com/ & Digital puzzle \\
\hline
\end{tabular}

\subsection{Linking Learning Objects to HTML Pages (e-book)}

Links for learning objects can be accomplished by using a free HTML editor (e.g. CoffeeCup Free HTML editor) directly on the HTML webpage using either the Shadowbox technique (Figure 1) or mouse over (Figure 2); the student is not obliged to switch to a new webpage (Figure 3), which can be confusing and could lead to disorientation.

<a href="extras/Html/kef1 en2 kouiz popup.htm"

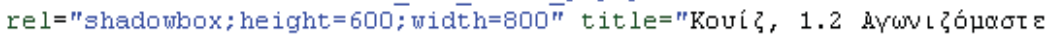

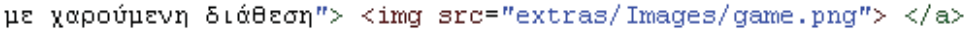

Figure 1: Learning object link in HTML with Shadowbox and mouse over.

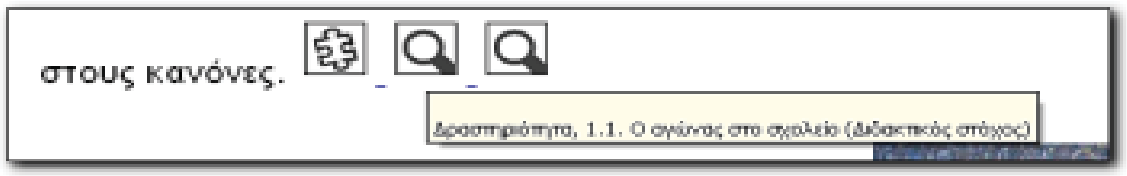

Figure 2: Using mouse over on the icon linked to the learning object.
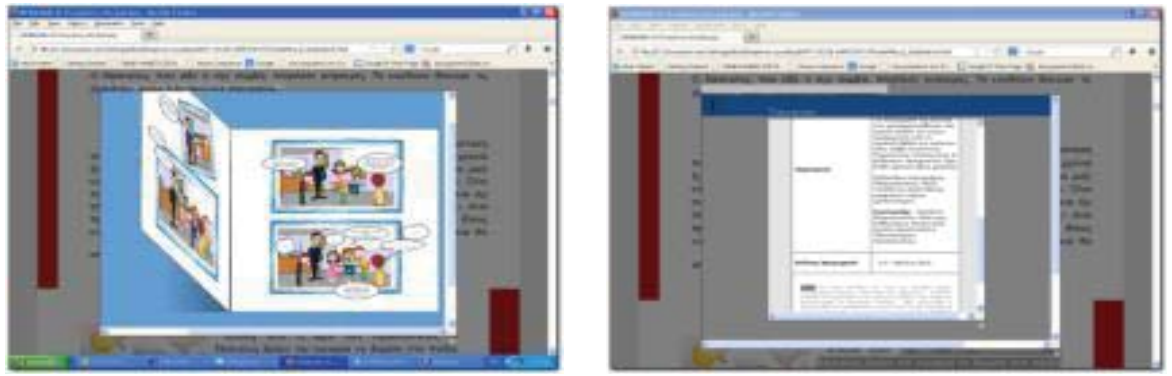

Figure 3: (a) Shadowbox view of a linked learning object (interactive comic) (b), Shadowbox view of learning object information.

The integration of the code of Figure 4 at the beginning of each HTML page is mandatory for Shadowbox functionality as well as CSS application - Cascading Style Sheets.

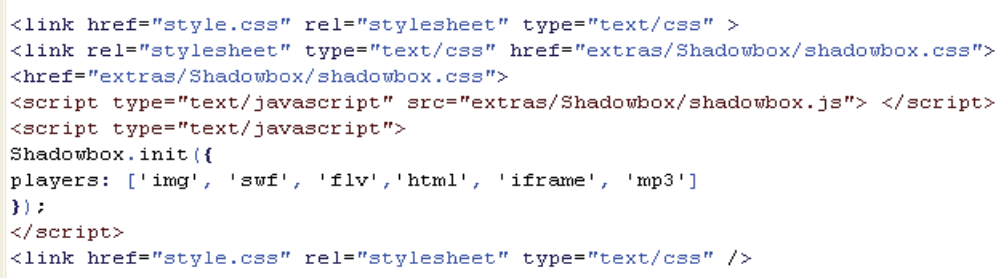

Figure 4: Source code integration in HTML for Shadowbox functionality. 


\subsection{Using eAnagnosis Software for Learning Object Linkage}

Marginalia family of eAnagnosis applications (Composer \& Paspartu) offers satisfactory solutions to meet the need for reading and creating enriched digital books with learning object incorporation. Specifically, Marginalia Paspartu software offers enriched digital books authoring. Similarly Marginalia Composer software is a viewer of enriched digital books or simple e-books in pdf or ePUB format. Figure 5 below illustrates learning object linkage capabilities of the software.

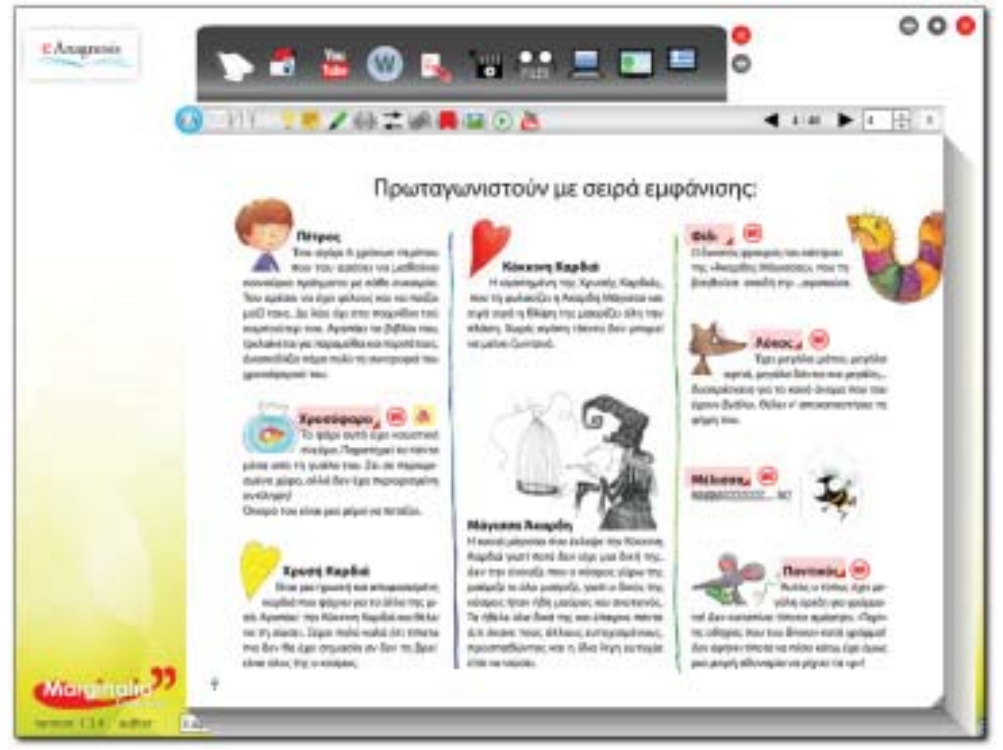

Figure 5: Using eAnagnosis for learning object linkage.

Digital enrichment is achieved though the use of Marginalia Paspartu toolbar options shown in Figure 6.

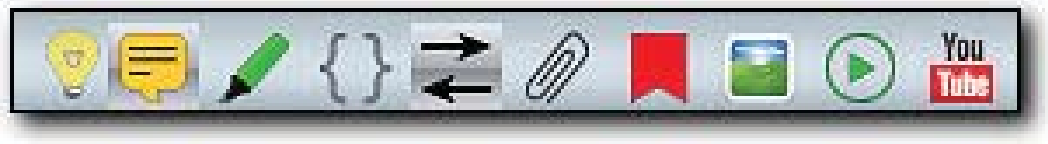

Figure 6: Digital enrichment toolbar.

The main functions of the digital enrichment toolbar are the following: a) hide notes, b) create a note with the nested notepad, c) underline, d) create hooks for boundary delineation of text or image area, e) insert bookmark, f) insert video, g) insert YouTube video. In all the above functions it is also possible to integrate the digital resource in the text or in the image and when it is mouse activated (double click) an inset window is displayed, accompanied by informative text, insert title option, internet address, digital resource deletion and importance setting of the digital resource with special colour marking (normal, interesting, remarkable, critical, attention).

\section{Conclusions and Future Work}

In the field of folklore education learning objects can upgrade the relationship between onsite folk research and school project on local history and folk culture. Internet and Web 2.0 tools can offer force and special individuality in folk culture documents.

By using Web 2.0 technology we can create learning objects that can be incorporated in digitally enriched e-books or digital repositories, contributing to folk culture enhancement through preservation, documentation and promotion of 
folk culture in school and in numerous educational areas (museums, libraries, files, educational projects). In the framework set by Web 2.0 technologies, learning object creation and digitally enriched e-book development on folk culture can be achieved alternatively by the tutor (learning resources) and the student (learning assets) producing valuable classroom digital material.

\section{References}

Ariadne (2000). Alliance of remote instructional authoring and distribution networks for Europe. Retrieved June 25, 2013, from http://ariadne.unil.ch/

ESCOT (2000). Educational software components of tomorrow website. Retrieved June 25, 2013, from http://www.escot.org/

Gasouka, M., \& Foulidis, X. (2012). New horizons of Folklore Studies - Conceptual Framework, Research, Gender, Internet and School. (pp. 104-105). Athens: Sideris.

Gasouka, M., Kapaniaris, A., Arvanitidou, Z., Foulidi, X., Raptou, E. (2013), "Folk culture and digital enriched books: The case study of the digital enriched tool "E-ANAGNOSIS". In Gómez L., et al. (Ed.), 7th International Technology, Education and Development Conference: (pp. 4176-4184). Valencia: International Association of Technology, Education and Development.

IEEE (2002). 1484.12.1-2002, Standard for Learning Object Metadata. The Institute of Electrical and Electronics Engineers, Inc. Retrieved June 25, 2013, from http://standards.ieee.org/findstds/standard/1484.12.1-2002-Cor_1-2011.html

Kapaniaris, A., \& Papadimitriou, E. (2012). Informatics Literacy in the Digital School. (pp. 50-52). Thessaloniki: Ziti.

Komis, V., (2004), Introduction to ICT education applications. (pp. 76,84). Athens: New Technologies Publications.

L'Allier, J. J. (1997). Frame of reference: NETg's map to the products, their structure and core beliefs. Research and Development NETg. Retrieved June 25, 2013, from http://web.archive.org/web/20020615192443/www.netg.com/research/ whitepapers/frameref.asp

LTSC (2000). Learning technology standards committee. IEEE Learning Technology Standards Committee (LTSC). Retrieved June 25, 2013, from http://www.ieeeltsc.org:8080/Plone

Marginalia Composer. (2013). Retrieved June 25, 2013, from http://www.eanagnosis.gr/

Merlot (2000). Multimedia educational resource for learning and on-line teaching. Retrieved June 25, 2013, from http://www.merlot.org/merlot/index.htm

Polsani, P. R. (2003). Use and abuse of reusable learning objects. Journal of Digital Information, 3(4). Retrieved June 25, 2013, from http://journals.tdl.org/jodi/index.php/jodi/article/view/89/88

Sasiakos, K., (2009), Pedagogic applications for PC. Professors' training handbook OAED, Athens: ASPETE.

Stefanou, X., (2002), An Architecture for Leaning Object Management on the Internet. In Dimitrakopoulou, A., (Ed.), 3rd Conference, ICT in Education, Vol. A', Rhodes: Kastaniotis - ETPE.

Wiley, D. A. (2000). Connecting learning objects to instructional design theory: A definition, a metaphor, and a taxonomy. In D. A. Wiley (Ed.), The Instructional Use of Learning Objects. Digital Learning Environments Research Group - The Edumetrics Institute. Retrieved June 25, $2013 \mathrm{http}: / / w e s r a c . u s c . e d u / w i r e d / b l d g-7 \_$file/wiley.pdf 